\title{
Anaemia in infancy in rural Bangladesh: contribution of iron deficiency, infections and poor feeding practices
}

\author{
Rahul Rawat ${ }^{1 *}$, Kuntal Kumar Saha ${ }^{2}$, Andrew Kennedy ${ }^{1}$, Fabian Rohner ${ }^{3}$, Marie Ruel ${ }^{1}$ \\ and Purnima Menon ${ }^{4}$ \\ ${ }^{1}$ Poverty Health and Nutrition Division, International Food Policy Research Institute (IFPRI), Washington DC, USA \\ ${ }^{2}$ IFPRI, Dhaka, Bangladesh \\ ${ }^{3}$ GroundWork LLC, Crans-près-Céligny, Switzerland \\ ${ }^{4}$ IFPRI, New Delhi, India
}

(Submitted 22 November 2012 - Final revision received 13 May 2013 - Accepted 13 May 2013 - First published online 17 June 2013)

\begin{abstract}
Few data exist on the aetiology of anaemia and Fe deficiency (ID) during early infancy in South Asia. The present study aimed to determine the contribution of ID, infections and feeding practices to anaemia in Bangladeshi infants aged 6-11 months. Baseline data from 1600 infants recruited into a cluster-randomised trial testing the effectiveness of micronutrient powder sales by frontline health workers on the prevalence of anaemia were used. Multivariate logistic regression was used to identify risk factors for anaemia and ID, and population attributable fractions (PAF) were computed to estimate the proportion of anaemia that might be prevented by the elimination of individual risk factors. It was found that $68 \%$ of the infants were anaemic, $56 \%$ were Fe deficient, and one-third had evidence of subclinical infections. The prevalence of anaemia and ID increased rapidly, until 8-9 months of age, while that of subclinical infections was constant. ID (adjusted OR (AOR) 2.6-5.0; $P<0.001$ ) and subclinical infections (AOR 1.4-1.5; $P<0.01$ ) were major risk factors for anaemia, in addition to age and male sex. Similarly, subclinical infections, age and male sex were significant risk factors for ID. Previous-day consumption of Ferich foods was very low and not associated with anaemia or ID. The PAF of anaemia attributable to ID was $67 \%$ (95\% CI 62, 71) and that of subclinical infections was 16\% (95\% CI 11,20). These results suggest that a multipronged strategy that combines improvements in dietary Fe intake alongside infection control strategies is needed to prevent anaemia during infancy in Bangladesh.
\end{abstract}

\section{Key words: Anaemia: Iron deficiency: Infections: Feeding practices: Infants: Bangladesh}

Anaemia remains one of the most common and intractable public health problems, particularly in developing countries. According to global estimates, as many as two billion people worldwide suffer from anaemia, with pregnant women, adolescent girls, and infants and young children facing the greatest burden of this disease ${ }^{(1,2)}$. The causes of anaemia are multifactorial, including nutritional deficiencies, infections and blood disorders ${ }^{(1,3)}$.

A crude but often cited estimate suggests that as much as $50 \%$ of anaemia can be attributed to Fe deficiency globally ${ }^{(2)}$. The global burden of Fe deficiency has been estimated from anaemia prevalence surveys, and though the methodology has its limitations, the estimates are large and point to a major public health problem. The WHO has estimated that $41 \%$ of women and $27 \%$ of preschool children suffer from anaemia due to Fe deficiency ${ }^{(2)}$, with considerable variability by geography and age group. The consequences of
Fe-deficiency anaemia (IDA) have been well documented ${ }^{(1,4-6)}$. In children, IDA is associated with delayed or impaired cognitive and physical development. Among adults, IDA may result in reduced physical work capacity and productivity. Anaemic women and children are at a greater risk of dying during the perinatal period. The economic consequence of Fe deficiency (ID), resulting from motor and mental impairment in children and low work productivity in adults, estimated from ten developing countries, is $4 \%$ of gross domestic product ${ }^{(7)}$.

During the first 6 months of life, full-term, normalbirth-weight babies are virtually self-sufficient with regard to their Fe needs. These babies are born with sufficient $\mathrm{Fe}$ stores to meet their physiological Fe needs ${ }^{(8)}$. Though $\mathrm{Fe}$ concentrations in breast milk are very low, $\mathrm{Fe}$ is in a highly bioavailable form. The combination of high $\mathrm{Fe}$ stores at birth and limited, but highly bioavailable, Fe in breast milk

Abbreviations: AGP, $\alpha$-1-acid glycoprotein; CRP, C-reactive protein; HH, household; ID, Fe deficiency; IDA, Fe-deficiency anaemia;

IYCF, infant and young child feeding; PF, plasma ferritin; TfR, soluble transferrin receptor. 
ensures that no additional $\mathrm{Fe}$ is required until approximately 6 months of age, after which requirements increase rapidly at a time when hepatic Fe stores accumulated during gestation are depleted. Fe requirements during the 6-11-month age period are higher than those at any other period of life, corresponding to rapid infant growth and brain development. Beginning at approximately 6 months of age, infants require additional sources of Fe to prevent Fe deficiency and its ensuing sequelae. Typically, this additional source of $\mathrm{Fe}$ is found in Fe-rich complementary foods, which may be meat products or Fe-fortified foods. In developing countries, the low availability and lack of access to Fe-fortified foods or costly animal-source foods and the poor Fe bioavailability in typical cereal-based complementary foods place large numbers of children at an increased risk of developing ID and anaemia during the critical complementary feeding phase.

While being born with a full endowment of Fe stores and ensuring adequate dietary Fe intake after 6 months of age are critical to prevent the development of anaemia among infants and young children, these alone are insufficient in the presence of infections. Infection control is an essential complementary strategy. Anaemia brought about by infections, referred to as anaemia of inflammation or anaemia of chronic disease, is mediated by pro-inflammatory cytokines that induce changes in Fe homeostasis, the proliferation of erythroid progenitor cells, the production of erythropoietin and the lifespan of erythrocytes, all of which contribute to the pathogenesis of anaemia $^{(9)}$. Additionally, during inflammation, pro-inflammatory cytokines stimulate the production of the hormone hepcidin, which in turn reduces Fe absorption, independent of Fe status, leading to tissue Fe deficiency ${ }^{(10)}$.

In Bangladesh, estimates suggest that anaemia affects twentyseven million children, adolescents and women and that the economic costs are up to $7.9 \%$ of gross domestic product ${ }^{(11)}$. The objectives of the present study were to examine the contribution that ID, infections and feeding practices make to anaemia, among Bangladeshi infants during the critical early complementary feeding period between 6 and 11 months of age. A strength of the present analysis is the availability of multiple Fe status indicators and markers of subclinical infections that allows for a close examination of the proportion of anaemia that is due to ID, infections and poor feeding practices. This information can help guide the development of targeted interventions that can alleviate the burden that anaemia and ID impose on rural Bangladeshi infants.

\section{Methods}

\section{Study design and population}

The present study was conducted in twenty subdistricts (upazillas) in rural Bangladesh that are part of BRAC's Essential Health Care programme. Baseline results are presented from a survey of 1600 infants aged 6-11 months who were recruited from 200 villages into a cluster-randomised $2 \times 2$ factorial design study investigating the impact of the sale of micronutrient powders (Pushtikona) by frontline health workers to households (HH) with young children and/or targeted behaviour change communication interventions to improve infant and young child feeding (IYCF) practices. $\mathrm{HH}$ were randomly selected based on the presence of a child aged 6-11 months who resided in the HH.

Data collection was conducted between April and June 2010. Trained interviewers visited the $\mathrm{HH}$ and administered a questionnaire that included demographic, health, nutrition, food security and socio-economic information at the child, maternal and $\mathrm{HH}$ levels. Over $95 \%$ of eligible $\mathrm{HH}$ were approached for the study and they consented, and $98.5 \%$ of all $\mathrm{HH}$ provided a blood sample for a child of 6-11 months of age. The HH questionnaire for the survey was based on the UNICEF conceptual framework on the causes of undernutrition ${ }^{(12)}$.

The present study was conducted according to the guidelines laid down in the Declaration of Helsinki, and all procedures involving human subjects were approved by the Bangladesh Medical Research Council and the Institutional Review Board at the International Food Policy Research Institute. Verbal informed consent was obtained from all subjects. Verbal consent was witnessed and formally recorded.

\section{Biomarker collection and processing}

Trained phlebotomists collected one drop of blood through great toe pricks from all infants of 6-11 months of age for $\mathrm{Hb}$ measurements, which were carried out using a Hemocue haemoglobinometer (Hb 201+; HemoCue America). An additional $300 \mu \mathrm{l}$ of blood were collected in lithium-heparin-coated microvettes (CB 300; Sarstedt) for additional biomarker assessments. Immediately after phlebotomy, these pre-labelled microvettes were placed in an ice chest/cold box with ice packs, maintained at $4{ }^{\circ} \mathrm{C}$ for transportation to a central laboratory in Dhaka. Blood samples were transported from the field to Dhaka on a daily basis and were processed no later than $24 \mathrm{~h}$ after phlebotomy. Precautions were taken to maintain proper temperature and to avoid physical shocks in order to prevent haemolysis of blood cells during transportation. On arrival in Dhaka, the blood samples were centrifuged for plasma separation. For analysis, $100 \mu \mathrm{l}$ of plasma were aliquoted. The remaining plasma was aliquoted separately and stored as back-up. Pre-printed labels having identical numbers were provided to the technicians at the central laboratory for use on the aliquots containing plasma before placing them in the freezer. The samples were temporarily stored in a freezer at $-20^{\circ} \mathrm{C}$ in the central laboratory until shipment on dry ice for further analyses. Retinol-binding protein, C-reactive protein (CRP), $\alpha$-1-acid glycoprotein (AGP), plasma ferritin (PF) and soluble transferrin receptor (TfR) levels were measured at the 'VitA-Fe Tech' laboratories (Willstaett, Germany) by a combined sandwich ELISA ${ }^{(13)}$. The CV (\% CV) for these tests ranged from a low value of $3.67 \%$ for AGP to a high value of $5.58 \%$ for CRP.

\section{Anthropometry and infant and young child feeding practices}

Anthropometric measures included weight and recumbent length measurements of infants and weight and height measurements of their mothers. The weights of children and 
mothers were measured using the Health-O-meter ${ }^{\circledR}$ electronic scales (Sunbeam Products, Inc.) and recorded to the nearest $100 \mathrm{~g}$. Locally manufactured, collapsible length/height boards, which were precise to $1 \mathrm{~mm}$, were used to measure the recumbent length of infants and the standing height of mothers. All anthropometrists underwent rigorous training on the standardisation process ${ }^{(14)}$.

Child feeding practices were assessed using the WHO-recommended methodology based on the previousday recall ${ }^{(15)}$. This method and the indicators that can then be created are widely accepted and used to capture optimal feeding practices in populations. Optimal IYCF practices captured by these indicators cover a range of practices and criteria to assess the adequacy of these practices. These include age-appropriate breast-feeding practices (timing, duration and exclusivity) and timely introduction and adequate frequency of consumption and type of complementary foods, including consumption of Fe-rich foods.

\section{Data analysis}

Recognising the effect that subclinical infections have on micronutrient status indicators, attempts were made to control for this by measuring two different markers of inflammation AGP and CRP - that capture both acute (CRP) and chronic (AGP) inflammation ${ }^{(16)}$. Subclinical infections were defined using a combination of elevated values of either AGP or CRP inflammation markers categorised by an AGP value $>1 \mathrm{~g} / \mathrm{l}$ or a CRP value $>5 \mathrm{mg} / \mathrm{l}$.

The following three different iron status indicators were measured: $\mathrm{Hb}$; PF; TfR. Anaemia was defined as a $\mathrm{Hb}$ value $<105 \mathrm{~g} / \mathrm{l}$. This cut-off is lower than the $110 \mathrm{~g} / \mathrm{l}$ cut-off proposed by the WHO and Centers for Disease Control (CDC) for children aged 6 months to 5 years. However, the $105 \mathrm{~g} / \mathrm{l}$ cut-off reflects the only reference value derived from $\mathrm{Fe}$ supplementation data that were collected from breast-fed infants ${ }^{(8)}$ and is frequently used by researchers. Severe anaemia was defined as a $\mathrm{Hb}$ cut-off $<70 \mathrm{~g} / \mathrm{l}^{(17)}$. We used three different definitions of ID using established cut-offs for PF and TfR. First, ID using the PF cut-off alone, after PF concentrations were adjusted for the presence of inflammation according to the methodology proposed by Thurnham et al. ${ }^{(18)}$, was defined as a PF value $<12 \mu \mathrm{g} / \mathrm{l}$. Second, ID using the TfR cut-off alone was defined as a TfR value $>8.3 \mathrm{mg} / \mathrm{l}$. Third, ID was also derived using either the low PF or elevated TfR values given above. IDA was defined using combinations of the ID definitions given above and the anaemia definition. In analyses that examined the determinants of Fe stores among infants, the ID definition using the PF cut-off was used. Vitamin A deficiency was defined as a retinol-binding protein concentration $<0.7 \mu \mathrm{mol} / 1$.

Weight and length measurements were used to derive $Z$-scores by comparing each child's anthropometric measurements with the 2006 WHO child growth standards for his/her age and sex. The three indicators created were length-for-age $Z$-score, weight-for-age $Z$-score and weight-for-length $Z$-score. Stunting is defined as a length-for-age $Z$-score $<-2$, underweight is defined as a weight-for-age $Z$-score $<-2$ and wasting is defined as a weight-for-length $Z$-score $<-2 Z$-scores ${ }^{(19)}$.
Statistical analysis was conducted using STATA 11 (Stata Corp). An initial exploratory analysis was performed to generate descriptive statistics of the study population. Statistical trends of micronutrient status indicators were examined by age trends using the nptrend command in STATA. Bivariate and multivariate logistic regression models were run using the logistic command to generate OR. These models adjusted for the clustering of data at the unit of randomisation level (the subdistrict) using the cluster option in STATA.

Logistic regression analysis was used to model known predictors of anaemia; the models also included known or hypothesised confounding factors. These include (1) age, sex, nutritional status (child underweight), subclinical infections, ID, previous-day consumption of Fe-rich foods (defined as flesh and organ meat, fish, fortified infant foods and formulas, and micronutrient powders containing $\mathrm{Fe})^{(15)}$ and the IYCF indicator representing a minimum acceptable diet at the level of the child; (2) maternal short stature (height $<145 \mathrm{~cm}$ ) and education (quartiles of years of schooling); (3) $\mathrm{HH}$ size and total $\mathrm{HH}$ expenditure. Total $\mathrm{HH}$ expenditure (including food and non-food items) during the previous $30 \mathrm{~d}$ was obtained from each $\mathrm{HH}$, and quartiles were derived and used in all analyses as a proxy of socio-economic status. The logit model for ID included all variables in the anaemia model, as well as maternal perception of relative birth size, as a proxy for birth weight data, which were unavailable. These variables were retained in the model being tested, regardless of whether they were significantly associated with the outcome variable in bivariate analyses. Adjusted population attributable fractions of anaemia were calculated from the multivariate logistic regression models using the aflogit command in STATA to estimate the proportion of anaemia in this population that might be prevented by the elimination of individual risk factors. A $P$ value $<0.05$ was considered significant for all inferential statistics, except for interactions that were considered significant at a $P$ value $<0 \cdot 10$.

\section{Results}

\section{Descriptive statistics}

Of the 1600 infants aged 6-11 months recruited into the present study, blood samples were available for 1579 infants, and complete biomarker data were available for 1497 infants. There were no differences in demographic characteristics for those infants who had complete biomarker data compared with the full sample. Given the known influence that subclinical infections have on micronutrient status indicators, study characteristics are presented for both the whole study population and the subsample in whom inflammation was absent (Table 1). With the exception of PF, CRP and AGP concentrations, there were no differences in demographic or biological characteristics between the full sample and subsample. The burden of subclinical infections was high in this sample population with over one-third of all infants being classified as having some subclinical infection based on either elevated AGP or CRP levels. Anaemia was highly prevalent, with over $68 \%$ of the infants having $\mathrm{Hb}$ concentrations 
Table 1. Sample characteristics

(Mean values and standard deviations; geometric means, percentages and $95 \%$ confidence intervals)

\begin{tabular}{|c|c|c|c|c|}
\hline & \multicolumn{2}{|c|}{ Full sample ( $n$ 1497) } & \multicolumn{2}{|c|}{$\begin{array}{l}\text { Subsample (individuals } \\
\text { without inflammation) }{ }^{\star}(n \text { 951) }\end{array}$} \\
\hline & Mean & SD & Mean & SD \\
\hline Maternal age (years) & $25 \cdot 9$ & $5 \cdot 8$ & $26 \cdot 0$ & $5 \cdot 7$ \\
\hline Maternal height $(\mathrm{cm})$ & $150 \cdot 8$ & $5 \cdot 4$ & $151 \cdot 1$ & $5 \cdot 5$ \\
\hline Child's age (months) & $8 \cdot 3$ & 1.7 & $8 \cdot 3$ & 1.7 \\
\hline Household size & 5.6 & $2 \cdot 3$ & $5 \cdot 6$ & $2 \cdot 3$ \\
\hline Monthly household expenditure (taka) & $9748 \cdot 0$ & $6277 \cdot 8$ & $9980 \cdot 2$ & $6452 \cdot 4$ \\
\hline $\mathrm{Hb}(\mathrm{g} / \mathrm{l})$ & $99 \cdot 3$ & $11 \cdot 1$ & 99.9 & 11.4 \\
\hline \multicolumn{5}{|l|}{ Unadjusted PF $(\mu \mathrm{g} / \mathrm{l})$} \\
\hline Geometric mean & \multirow{2}{*}{\multicolumn{2}{|c|}{$\begin{array}{c}34 \cdot 0 \\
32 \cdot 8,35 \cdot 3\end{array}$}} & \multirow{2}{*}{\multicolumn{2}{|c|}{$\begin{array}{c}29 \cdot 3 \\
28 \cdot 1,30 \cdot 7\end{array}$}} \\
\hline $95 \% \mathrm{Cl}$ & & & & \\
\hline \multicolumn{5}{|l|}{ Adjusted PF† ( $\mu \mathrm{g} / \mathrm{l})$} \\
\hline Geometric mean & \multirow{2}{*}{\multicolumn{2}{|c|}{$\begin{array}{c}29 \cdot 3 \\
28 \cdot 3,30 \cdot 4\end{array}$}} & \multicolumn{2}{|c|}{-} \\
\hline $95 \% \mathrm{Cl}$ & & & & \\
\hline TfR (mg/l) & $9 \cdot 7$ & 4.5 & $9 \cdot 8$ & $4 \cdot 7$ \\
\hline AGP $(g / l)$ & 0.9 & 0.3 & 0.8 & 0.1 \\
\hline CRP (mg/l) & $3 \cdot 3$ & $6 \cdot 8$ & 0.8 & 0.9 \\
\hline $\mathrm{RBP}(\mu \mathrm{mol} / \mathrm{l})$ & 0.9 & 0.3 & 1.0 & 0.2 \\
\hline LAZ & $-1 \cdot 1$ & 1.4 & $-1 \cdot 1$ & 1.4 \\
\hline WLZ & -0.9 & 1.3 & -0.9 & $1 \cdot 2$ \\
\hline \multirow[t]{2}{*}{ WAZ } & -1.4 & $1 \cdot 2$ & $-1 \cdot 3$ & $1 \cdot 1$ \\
\hline & $\%$ & $95 \% \mathrm{Cl}$ & $\%$ & $95 \% \mathrm{Cl}$ \\
\hline Female & \multicolumn{2}{|c|}{49.5} & \multicolumn{2}{|c|}{$49 \cdot 9$} \\
\hline Anaemia $(\mathrm{Hb}<105 \mathrm{~g} / \mathrm{l})$ & $68 \cdot 1$ & $65 \cdot 8,70 \cdot 5$ & $64 \cdot 7$ & $61 \cdot 6,67 \cdot 7$ \\
\hline Anaemia $(\mathrm{Hb}<110 \mathrm{~g} / \mathrm{l})$ & 83.5 & $81 \cdot 6,85 \cdot 4$ & $81 \cdot 1$ & $78 \cdot 6,83 \cdot 6$ \\
\hline ID (TfR $>8.3 \mathrm{mg} / \mathrm{l})$ & $55 \cdot 7$ & $53 \cdot 2,58 \cdot 2$ & $53 \cdot 8$ & $50 \cdot 7,57 \cdot 0$ \\
\hline ID (adjusted PF† $<12 \mu \mathrm{g} / \mathrm{l}$ ) & 9.9 & $8 \cdot 5,11.4$ & $10 \cdot 6$ & $8 \cdot 7,12 \cdot 6$ \\
\hline ID (adjusted PF† or TfR) & $56 \cdot 5$ & $53 \cdot 9,59 \cdot 0$ & $54 \cdot 7$ & $51 \cdot 5,57 \cdot 8$ \\
\hline Inflammation (AGP > 1 g/l) & $34 \cdot 0$ & $31 \cdot 6,36 \cdot 4$ & - & - \\
\hline Inflammation (CRP > 5 mg/l) & $14 \cdot 2$ & $12 \cdot 5,16 \cdot 0$ & - & - \\
\hline Any inflammation (AGP $>1 \mathrm{~g} / \mathrm{l}$ or CRP $>5 \mathrm{mg} / \mathrm{l})$ & $36 \cdot 3$ & $33 \cdot 8,38 \cdot 7$ & - & - \\
\hline IDA (anaemia and TfR $>8.3 \mathrm{mg} / \mathrm{l}$ ) & $43 \cdot 3$ & $40 \cdot 8,45 \cdot 8$ & $40 \cdot 7$ & $37 \cdot 6,43 \cdot 8$ \\
\hline IDA (anaemia and adjusted PF† $<12 \mu \mathrm{g} / \mathrm{l}$ ) & $9 \cdot 6$ & $8 \cdot 1,11 \cdot 0$ & $9 \cdot 7$ & $7 \cdot 9,11 \cdot 7$ \\
\hline IDA (adjusted PF† or TfR) & $43 \cdot 9$ & $41 \cdot 4,46 \cdot 5$ & 41.4 & $38 \cdot 3,44 \cdot 6$ \\
\hline $\operatorname{VAD}(\mathrm{RBP}<0.7 \mu \mathrm{mol} / \mathrm{l})$ & $17 \cdot 8$ & $15 \cdot 9,19 \cdot 8$ & $10 \cdot 0$ & $8 \cdot 1,11.9$ \\
\hline Consumption of Fe-rich foods & $13 \cdot 6$ & $11 \cdot 9,15 \cdot 3$ & $14 \cdot 1$ & $11 \cdot 9,16 \cdot 3$ \\
\hline Minimum acceptable diet & $6 \cdot 1$ & $4 \cdot 9,7 \cdot 3$ & $6 \cdot 2$ & $4 \cdot 7,7 \cdot 7$ \\
\hline Stunted $\ddagger$ & $25 \cdot 5$ & $23 \cdot 3,27 \cdot 6$ & $22 \cdot 9$ & $20 \cdot 2,25 \cdot 6$ \\
\hline Wasted§ & $17 \cdot 9$ & $16 \cdot 0,19 \cdot 8$ & $15 \cdot 8$ & $13 \cdot 5,18 \cdot 1$ \\
\hline Underweight|| & $27 \cdot 8$ & $25 \cdot 5,30 \cdot 0$ & $25 \cdot 1$ & $22 \cdot 4,27 \cdot 9$ \\
\hline
\end{tabular}

PF, plasma ferritin; TfR, soluble transferrin receptor; AGP, $\alpha$-1-acid glycoprotein; CRP, C-reactive protein; RBP, retinol-binding protein; LAZ, length-forage Z-score; WLZ, weight-for-length Z-score; WAZ, weight-for-age Z-score; ID, Fe deficiency; IDA, Fe-deficiency anaemia; VAD, vitamin A deficiency. * $A G P>1 \mathrm{~g} / \mathrm{l}$ or CRP $>5 \mathrm{mg} / \mathrm{l}$.

†PF concentrations adjusted for inflammation.

$\ddagger \mathrm{LAZ}<-2$.

$\S W L Z<-2$.

$\| \mathrm{WAZ}<-2$

$<105 \mathrm{~g} / \mathrm{l}$. When the WHO-recommended cut-off $<110 \mathrm{~g} / \mathrm{l}$ was applied, the prevalence of anaemia increased to $84 \%$. The prevalence of ID, using either the PF or the TfR cut-off, was $57 \%$ in the full sample and $55 \%$ in the subsample. However, the prevalence differed markedly when ID was defined using the PF or TfR cut-off alone. The prevalence of ID was substantially higher when the TfR cut-off was used than on using the PF cut-off. Similarly, the prevalence of IDA varied depending on what criteria were used; the prevalence of IDA using either the PF or TfR cut-off in combination with the Hb cut-off was $44 \%$ in the full sample and $41 \%$ in the subsample. The burden of undernutrition as reflected by anthropometric indices was high in this population, especially considering the young age of our sample (6-11 months). Both stunting and wasting were highly prevalent, with $26 \%$ of the infants being stunted (mean length-for-age $Z$-score: $-1 \cdot 1$ (SD 1.4)) and $18 \%$ of the infants being wasted (mean weight-for-length $Z$-score: $-0.9(\operatorname{sD~1.3))}$.

In both the full sample and subsample, a consistent pattern of increasing prevalence of anaemia and ID with age was observed, up until 8 months (trend statistically significant for infants aged 6-8 months), after which prevalence remained high, but generally plateaued (trend not statistically significant for infants aged 9-11 months) (Fig. 1). Anaemia peaked 

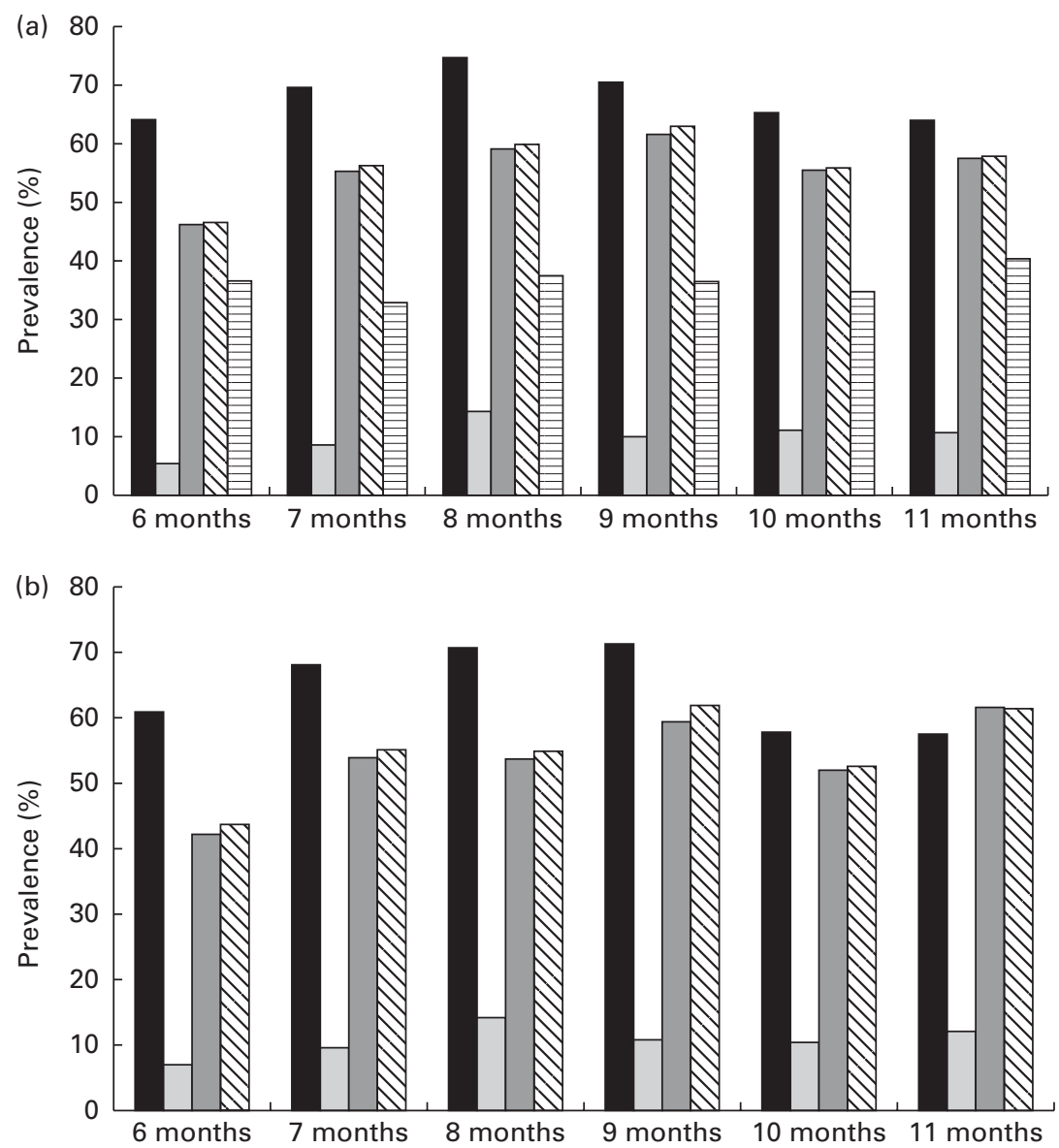

Fig. 1. Prevalence of anaemia, iron deficiency (ID) and subclinical infections in infants of 6-11 months of age, by age. (a) Full sample. There was a statistically significant $(P<0.001)$ trend for all indicators, except for inflammation, between 6 and 8 months of age. (b) Subsample (individuals without subclinical infections). There was a statistically significant $(P<0.001)$ trend for all indicators between 6 and 8 months of age. $\quad$, Anaemia (Hb concentration $<105 \mathrm{~g} /$ ); $\square$, ID (adjusted plasma ferritin (PF) $<12 \mu \mathrm{g} /$ ); $\square$, ID (soluble transferrin receptor (TfR) $>8.3 \mathrm{mg} / \mathrm{l})$; $\square$, ID (adjusted PF or TfR); घ, any inflammation $(\alpha-1$-acid glycoprotein $>1 \mathrm{~g} / \mathrm{I}$ or C-reactive protein $>5 \mathrm{mg} / \mathrm{l})$.

among infants of 8 months of age at $75 \%$, while ID (using a combination of either inflammation-corrected PF or TfR) peaked among infants of 9 months of age at $63 \%$. The prevalence of subclinical infections across age was roughly consistent, ranging from 31 to $38 \%$.

\section{Infant and young child feeding practices}

As expected, the consumption of all food groups increased with age (Fig. 2). By 11 months of age, however, only $23 \%$ of all infants had consumed Fe-rich foods during the previous day. In the 8- and 9-month age groups, the age range at which anaemia and Fe deficiency peak, only 13 and $16 \%$ of the infants, respectively, had consumed Fe-rich foods during the previous day. The most commonly consumed Fe-rich food was fish, which was consumed by up to $19 \%$ of the infants by 11 months of age. Overall, feeding practices, in particular complementary feeding practices, of infants in this population were suboptimal, with less than $14 \%$ of the infants having consumed Fe-rich foods on the previous day or having met the minimum recommended diversity in their diet and only $6 \%$ having met the criteria for a minimum acceptable diet.

\section{Risk factors for anaemia and iron deficiency: multivariate models}

In multivariate logistic regression models, ID (using one of the three ID classifications) and subclinical infections were consistently statistically significant predictors of anaemia (Table 2). No statistically significant association between IYCF practices and Fe status indicators was found when modelled either as continuous or categorical variables. Among infants who were Fe deficient, the odds of being anaemic were $2 \cdot 6-5 \cdot 0$ times higher (models 1,2 or 3 ) than those in infants not deficient $(P<0.001)$ and $1.4-1.5$ times higher (models 1, 2 or 3) among infants with subclinical infections $(P<0.01)$ than in those without subclinical infections. There were no differences by age group, with the exception of the 8-month-old infants who had a statistically significant higher risk of being anaemic $(P<0 \cdot 05)$, compared with the reference group of infants of 6 months of age. Additional risk factors for anaemia were short maternal stature $(<145 \mathrm{~cm})$ and being male. HH socio-economic status, previous-day consumption of Fe-rich foods and the combined IYCF indicator of a minimum acceptable diet were not associated with anaemia. Population attributable fraction estimates show that $67 \%$ 


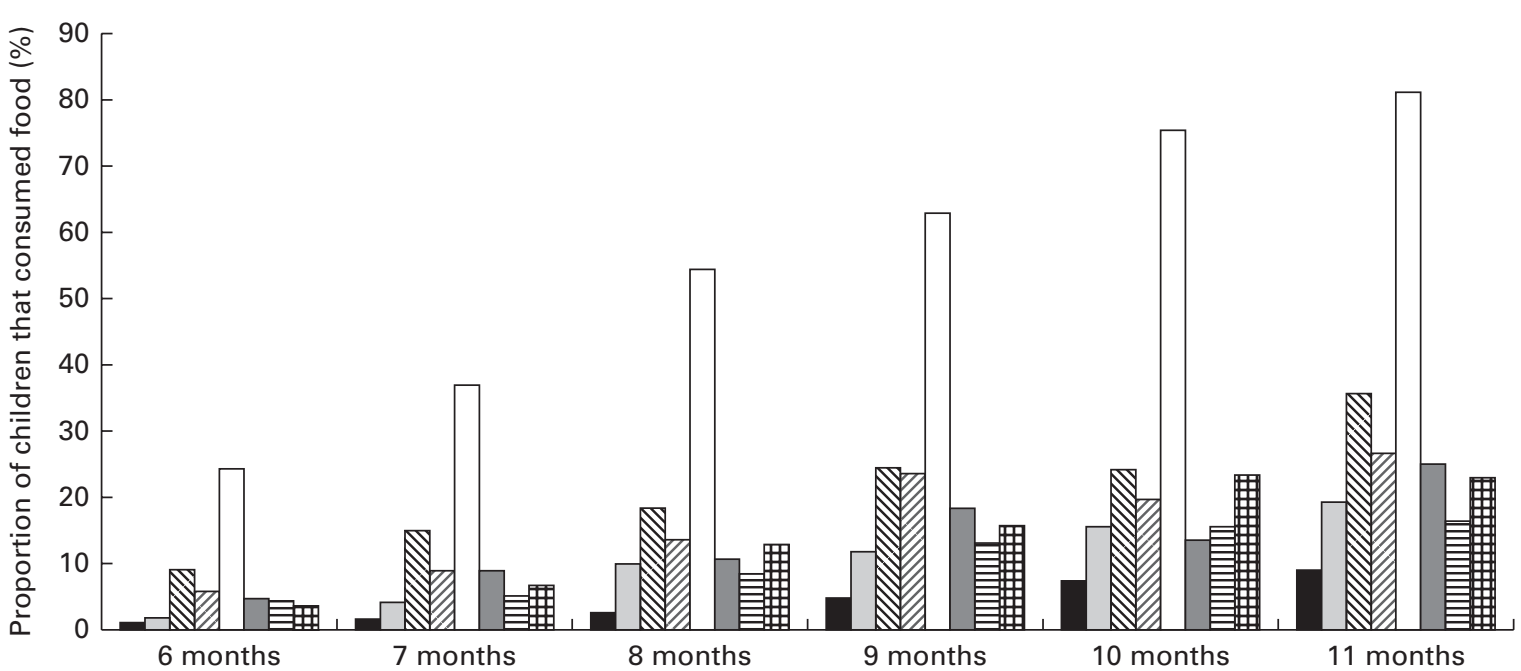

Fig. 2. Diversity of complementary foods fed to infants aged $6-11$ months in the past $24 \mathrm{~h}$, by age. There was a statistically significant $(P<0.001)$ trend for all

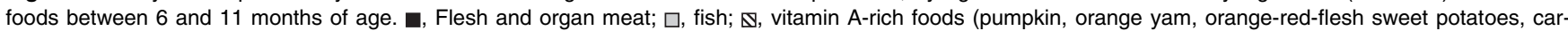
rots, ripe papaya or ripe mango); $\square$, green leafy vegetables; $\square$, rice; $\square$, pulses/lentils; $\boxminus$, eggs; 田, iron-rich foods (flesh and organ meat, fish, iron-fortified infant foods and formulas, and micronutrient powders).

(95\% CI 62,71$)$ of anaemia in this population might be prevented by the elimination of ID and $16 \%$ (95\% CI 11, 19) by eliminating subclinical infections.

Similarly, subclinical infections, age and male sex were also significant risk factors for ID (Table 3). Additionally, babies whose mothers recalled them being born small relative to other babies in their community had greater odds of being Fe deficient, with a clear linear relationship. When the analysis was restricted to individuals without subclinical infections (data not shown) and a PF cut-off $<12 \mu \mathrm{g} / \mathrm{l}$ was used to indicate true depleted Fe stores, infants of 8-9 months of age were at a greatest risk of having depleted Fe stores (adjusted OR $2 \cdot 00,95 \%$ CI $0 \cdot 9,4 \cdot 4)$, and males were at a greater risk than females (adjusted OR 2.2, 95\% CI 1.5, 3.3). Indicators of complementary feeding practices were not statistically associated with ID.

Though younger infants and those with subclinical infections were at a greatest risk of developing anaemia and ID, there were no differential associations between any other key risk factors such as consumption of Fe-rich foods or other IYCF indicators with subclinical infections or age; none of the tests for interactions between these variables and child age or subclinical infections was statistically significant.

\section{Discussion}

The present study reinforces the public health significance of anaemia, Fe deficiency and infections among infants of 6-11 months of age in rural Bangladesh. Anaemia affected $68 \%$ of the infants, whereas more than half of the infants suffered from ID and one-third had subclinical infections. The present findings also indicate that up to $67 \%$ of all cases of anaemia in this sample could be attributed to ID and $16 \%$ to infections.

By any measure, the prevalence estimates of anaemia are alarming, and higher than expected, based on previous data. According to the Bangladesh national strategy for anaemia prevention and control ${ }^{(11)}$, approximately $65 \%$ of children of 6-23 months of age are anaemic when using the WHO cutoff of $\mathrm{Hb}<110 \mathrm{~g} / \mathrm{l}$, compared with $84 \%$ of infants in our population using this standard. Two recent studies have reported prevalence estimates among infants of 6 months of age in rural Bangladesh of $46^{(20)}$ and $55 \%^{(21)}$ using the cut-off used in the present analysis. In the population of the present study, the prevalence of anaemia among infants of 6 months of age was $65 \%$. One plausible explanation for the higher prevalence of anaemia that we observed, compared with that reported in other studies carried out in Bangladesh, is the substantially higher prevalence of subclinical infections, which is more than twice as high as that observed in other reported studies.

The prevalence of ID varied significantly depending on the criteria used to define ID; using a combination of indicators that reflect either depleted Fe stores (PF) or decreased supply of Fe to tissues (TfR), it was observed that the prevalence of ID was $57 \%$. Reliable estimates of the prevalence of ID are scarce, given the wide set of indicators used to define ID and the influence that infections have on the more frequently used indicators. There is no global consensus as to which indicators are to be used to define ID particularly when infections are widespread. Rather, current recommendations urge the use of multiple Fe indicators as well as indicators of subclinical infections ${ }^{(1)}$ as has been done in the present study. However, these recommendations do not provide clarity on how exactly Fe indicators should be analysed in combination with the indicators of subclinical infections. The present study used a recently developed methodology ${ }^{(18)}$ that adjusts PF concentrations for the presence of inflammation. Given the use of multiple Fe status indicators, it is important to understand what each of these indicators indicates. PF is a measure of the amount of Fe in body stores, and concentrations below the cut-offs used in our analysis represent depleted Fe stores. TfR has greater utility as a functional indicator of Fe deficiency; it reflects the demand for $\mathrm{Fe}$ 
Table 2. Logistic regression models predicting anaemia in infants of $6-11.9$ months of age (Odds ratios and $95 \%$ confidence intervals)

\begin{tabular}{|c|c|c|c|c|c|c|c|c|}
\hline & \multirow{2}{*}{\multicolumn{2}{|c|}{$\begin{array}{l}\text { Bivariate analyses } \\
\quad \text { (unadjusted) }\end{array}$}} & \multicolumn{2}{|c|}{ Model 1} & \multicolumn{2}{|c|}{ Model 2} & \multicolumn{2}{|c|}{ Model 3} \\
\hline & & & \multicolumn{2}{|c|}{$\begin{array}{c}\text { ID (adjusted PF) } \\
(n 1485)\end{array}$} & \multicolumn{2}{|c|}{ ID (TfR) ( $n$ 1485) } & \multicolumn{2}{|c|}{$\begin{array}{l}\text { ID (adjusted PF } \\
\text { or TfR) }(n 1485)\end{array}$} \\
\hline & OR & $95 \% \mathrm{Cl}$ & OR & $95 \% \mathrm{Cl}$ & OR & $95 \% \mathrm{Cl}$ & OR & $95 \% \mathrm{Cl}$ \\
\hline ID (adjusted PF $\ddagger)$ & $5 \cdot 40^{\star \star \star}$ & $2.98,9.75$ & $5.02^{\star \star \star}$ & $2 \cdot 72,9 \cdot 26$ & & & & \\
\hline ID (TfRß) & $2 \cdot 78^{\star \star \star}$ & $2 \cdot 18,3.54$ & & & $2 \cdot 62^{\star \star \star}$ & $2.03,3.39$ & & \\
\hline ID (adjusted PF or TfR) & $2 \cdot 84^{\star \star *}$ & $2 \cdot 20,3.66$ & & & & & $2 \cdot 69^{\star \star \star}$ & $2.04,3.53$ \\
\hline Any inflammation & $1.56^{\star * *}$ & $1.28,1.90$ & $1 \cdot 50^{\star \star \star}$ & $1 \cdot 19,1 \cdot 88$ & $1.43^{\star \star}$ & $1 \cdot 12,1 \cdot 81$ & $1.43^{\star \star}$ & $1 \cdot 13,1.81$ \\
\hline VAD & $1.52^{\star \star}$ & $1 \cdot 12,2 \cdot 08$ & 1.27 & $0.90,1.80$ & 1.32 & $0.93,1.86$ & 1.31 & $0.92,1.85$ \\
\hline \multicolumn{9}{|l|}{ Sex } \\
\hline $\begin{array}{l}\text { Female } \\
\text { Age }(6 \text { months, reference) }\end{array}$ & $0 \cdot 66^{\star \star *}$ & $0.54,0.81$ & $0.72^{* *}$ & $0.57,0.90$ & $0.80 \dagger$ & $0.63,1.00$ & $0.80 \dagger$ & $0.63,1.02$ \\
\hline $\begin{array}{l}\text { Age ( } 6 \text { months, reference) } \\
7 \text { months }\end{array}$ & $1.28 t$ & $0.99,1.66$ & 1.25 & \multicolumn{5}{|c|}{ Age (6 months, reference) } \\
\hline 8 months & $1.65^{\star \star}$ & $1 \cdot 18,2 \cdot 32$ & $1.46^{*}$ & $1.02,2.07$ & $1.44^{*}$ & $1.02,2.03$ & $1.43^{\star}$ & $1.01,2.02$ \\
\hline 9 months & $1.33 \dagger$ & $0.98,1.81$ & $1 \cdot 21$ & $0.87,1.68$ & $1 \cdot 10$ & $0.78,1.56$ & 1.09 & $0.76,1.54$ \\
\hline 10 months & 1.05 & $0.77,1.43$ & 0.99 & $0.72,1.35$ & 0.95 & $0.67,1.34$ & 0.95 & $0.67,1.34$ \\
\hline 11 months & 0.99 & $0.74,1.34$ & 0.87 & $0.63,1.19$ & 0.81 & $0.58,1.13$ & 0.80 & $0.57,1.13$ \\
\hline $\mathrm{HH}$ size & 0.98 & $0.94,1.02$ & 1.00 & $0.94,1.06$ & 0.98 & $0.93,1.04$ & 0.98 & $0.93,1.04$ \\
\hline \multicolumn{9}{|l|}{ HH expenditure } \\
\hline Lowest quartile & 1.00 & & 1.00 & & 1.00 & & 1.00 & \\
\hline Second quartile & $1 \cdot 10$ & $0.81,1.49$ & $1 \cdot 13$ & $0.82,1.55$ & $1 \cdot 18$ & $0.83,1.66$ & 1.20 & $0.85,1.68$ \\
\hline Third quartile & $1 \cdot 15$ & $0.88,1.49$ & $1 \cdot 18$ & $0.86,1.63$ & $1 \cdot 19$ & $0.86,1.63$ & $1 \cdot 20$ & $0.88,1.65$ \\
\hline Highest quartile & 0.89 & $0.65,1.22$ & 0.98 & $0.63,1.53$ & 1.06 & $0.66,1.70$ & 1.07 & $0.67,1.71$ \\
\hline Underweight (WAZ <-2) & $1 \cdot 34^{* *}$ & $1.07,1.68$ & $1 \cdot 30^{*}$ & $1.00,1.67$ & $1 \cdot 26 \dagger$ & $0.97,1.62$ & $1 \cdot 27 \dagger$ & $0.98,1.64$ \\
\hline Minimum acceptable diet & $1 \cdot 28$ & $0.82,1.98$ & 1.29 & $0.80,2.09$ & 1.46 & $0.90,2.38$ & 1.43 & $0.90,2 \cdot 31$ \\
\hline Fe-rich foods & 0.92 & $0.68,1.23$ & 0.88 & $0.63,1.23$ & 0.91 & $0.64,1.29$ & 0.91 & $0 \cdot 64,1 \cdot 29$ \\
\hline Maternal short stature & $1.46^{*}$ & $1.03,2.06$ & 1.32 & $0.91,1.91$ & $1.37 \dagger$ & $1.00,1.88$ & $1.38^{*}$ & $1.01,1.88$ \\
\hline \multicolumn{9}{|l|}{ Maternal education } \\
\hline Lowest quartile & 1.00 & & 1.00 & & 1.00 & & 1.00 & \\
\hline Second quartile & 1.04 & $0.76,1.41$ & $1 \cdot 17$ & $0.84,1.63$ & $1 \cdot 20$ & $0.87,1.65$ & $1 \cdot 20$ & $0.87,1.66$ \\
\hline Third quartile & $0.76 \dagger$ & $0.57,1.00$ & 0.83 & $0.63,1.09$ & 0.81 & $0.60,1.10$ & 0.81 & $0.60,1.09$ \\
\hline Highest quartile & 0.93 & $1.79,2.95$ & 0.93 & $0.69,1.26$ & 0.96 & $0.70,1.31$ & 0.95 & $0.70,1.31$ \\
\hline
\end{tabular}

ID, Fe deficiency; PF, plasma ferritin; TfR, soluble transferrin receptor; VAD, vitamin A deficiency; HH, household; WAZ, weight-for-age Z-score.

${ }^{\star} P<0.05,{ }^{\star \star} P<0.01,{ }^{\star \star \star} P<0.001$

$\dagger P<0.1$.

$\ddagger$ Adjusted PF concentration $<12 \mu \mathrm{g} /$.

$\S$ TfR concentration $>8.3 \mathrm{mg} / \mathrm{l}$.

$\| \alpha$-1-Acid glycoprotein $>1 \mathrm{~g} / \mathrm{l}$ or C-reactive protein $>5 \mathrm{mg} / \mathrm{l}$.

ๆl Maternal height $<145 \mathrm{~cm}$.

and is a marker of the severity of Fe insufficiency only when Fe stores have been exhausted. TfR, unlike PF, is purported to be uninfluenced by inflammation. In the present study, these indicators were used separately and in combination in the multivariate analyses where ID was both an outcome of interest and a key determinant of anaemia.

In our sample, the risk of anaemia and ID increased significantly with age up until 8 months, after which the prevalence decreased slightly albeit remaining high. From the multivariate regression models, it was found that the risk of anaemia was greatest among 8-month-old infants, while the risk of ID was greatest among 8- or 9-month-old infants, depending on the definition of ID. This pattern of increased risk of anaemia up until approximately $8-9$ months of age within a narrow 6-month age range (6-11 months of age) was unexpected. An earlier study carried out in Nepal has reported anaemia rates to be increasing progressively from 4 until 17 months of age, with 15-17-month-old children being almost four times more likely to be anaemic than infants aged $4-5$ months ${ }^{(22)}$. The child feeding literature highlights the risk of anaemia and $\mathrm{Fe}$ deficiency associated with exclusive breastfeeding beyond 6 months of age ${ }^{(23,24)}$. However, in our sample, exclusive breast-feeding rates, even among the youngest age group (6-8 months of age), were low (2.9\%) and exclusive breast-feeding practice was not a significant predictor of anaemia when statistically modelled.

We posit that suboptimal infant feeding practices, and in particular very low consumption of Fe-fortified foods or animal-source foods, combined with the poor Fe bioavailability of cereal-based complementary foods consumed during the 6-8-month age period corresponding to a period of increasing physiological $\mathrm{Fe}$ requirements are the main reasons for the increasing risk of anaemia found between 6 and 8 months of age. Overall, consumption of Fe-rich foods was very low in our sample; only $13.6 \%$ had consumed such foods in the previous $24 \mathrm{~h}$. Consumption of Fe-rich foods increased slightly with age, but in the 6-8-month-old group (corresponding to the increasing prevalence of anaemia), only $6.3 \%$ had consumed flesh or organ meat on the previous day, $5.2 \%$ had consumed fish and $7 \cdot 7 \%$ had consumed any Fe-rich foods.

Our analyses did not show a statistically significant association between consumption of Fe-rich foods and ID. This may have been due to the small percentage of infants who 
Table 3. Logistic regression models predicting iron deficiency (ID) in infants of 6-11.9 months of age (Odds ratios and $95 \%$ confidence intervals)

\begin{tabular}{|c|c|c|c|c|c|c|}
\hline & \multirow{2}{*}{\multicolumn{2}{|c|}{$\begin{array}{c}\text { Model } 1 \\
\text { ID (adjusted PF }) \\
(n 1479)\end{array}$}} & \multicolumn{2}{|c|}{ Model 2} & \multicolumn{2}{|c|}{ Model 3} \\
\hline & & & \multicolumn{2}{|c|}{ ID (TfR§) (n 1479) } & \multicolumn{2}{|c|}{$\begin{array}{l}\text { ID (adjusted PF } \ddagger \text { or } \\
\text { TfR) }(n 1479\end{array}$} \\
\hline & OR & $95 \% \mathrm{Cl}$ & OR & $95 \% \mathrm{Cl}$ & OR & $95 \% \mathrm{Cl}$ \\
\hline Any inflammation\| & 1.07 & $0.77,1.51$ & $1.33^{\star}$ & $1.05,1.68$ & $1.32^{\star \star \star}$ & $1.06,1.65$ \\
\hline \multicolumn{7}{|l|}{ Sex } \\
\hline Female & $0.48^{\star \star \star}$ & $0.34,0.66$ & $0.46^{\star \star \star}$ & $0.41,0.51$ & $0.45^{\star \star \star}$ & $0.40,0.51$ \\
\hline \multicolumn{7}{|l|}{ Age (6 months, reference) } \\
\hline 7 months & $1.72^{*}$ & $1.05,2.82$ & $1.46^{\star}$ & $1.05,2.03$ & $1.52^{\star *}$ & $1.10,2.08$ \\
\hline 8 months & $2 \cdot 55^{\star \star}$ & $1.34,4.83$ & $1.67^{\star \star \star}$ & $1 \cdot 23,2 \cdot 25$ & $1 \cdot 69^{\star \star \star}$ & $1 \cdot 29,2 \cdot 23$ \\
\hline 9 months & 1.60 & $0.71,3.64$ & $1.84^{\star *}$ & $1 \cdot 23,2 \cdot 74$ & $1.93^{\star \star}$ & $1.25,2.98$ \\
\hline 10 months & $1.87 \dagger$ & $0.90,3.89$ & $1.47^{\star}$ & $1 \cdot 03,2 \cdot 11$ & $1.48^{\star}$ & $1 \cdot 01,2 \cdot 16$ \\
\hline 11 months & $1.64 \dagger$ & $0.95,2.82$ & $1.56^{\star \star}$ & $1 \cdot 10,2 \cdot 21$ & $1.57^{\star \star}$ & $1 \cdot 11,2 \cdot 21$ \\
\hline $\mathrm{HH}$ size & $0.88 \dagger$ & $0.79,0.98$ & 1.01 & $0.93,1.09$ & 1.00 & $0.92,1.09$ \\
\hline \multicolumn{7}{|l|}{$\mathrm{HH}$ expenditure } \\
\hline Lowest quartile & 1.00 & & 1.00 & & 1.00 & \\
\hline Second quartile & 1.06 & $0.58,1.90$ & 0.83 & $0.60,1.15$ & 0.77 & $0.55,1.07$ \\
\hline Third quartile & 1.46 & $0.86,2.47$ & 1.13 & $0.84,1.53$ & 1.06 & $0.78,1.43$ \\
\hline Highest quartile & $1 \cdot 21$ & $0.75,1.96$ & 0.78 & $0.53,1.15$ & 0.75 & $0.53,1.07$ \\
\hline Maternal short stature & 1.72 & $1.08,2.75$ & 1.13 & $0.79,1.62$ & 1.12 & $0.78,1.59$ \\
\hline \multicolumn{7}{|l|}{ Maternal education } \\
\hline Lowest quartile & 1.00 & & 1.00 & & 1.00 & \\
\hline Second quartile & 1.17 & $0.77,1.77$ & 0.95 & $0.69,1.29$ & 0.94 & $0.69,1.28$ \\
\hline Third quartile & 1.11 & $0.68,1.81$ & 1.08 & $0.72,1.62$ & 1.09 & $0.73,1.62$ \\
\hline Highest quartile & 0.82 & $0.45,1.47$ & 0.80 & $0.57,1.11$ & 0.81 & $0.59,1.10$ \\
\hline \multicolumn{7}{|l|}{ Perceived birth size } \\
\hline Very big & 1.00 & & 1.00 & & 1.00 & \\
\hline Bigger than average & 1.89 & $0.35,10.25$ & $2 \cdot 23^{\star}$ & $1.04,4.79$ & $2 \cdot 31^{*}$ & $1.11,4.84$ \\
\hline Average & $2 \cdot 18$ & $0.45,10.67$ & $1 \cdot 88^{*}$ & $1.01,3.49$ & $1.93^{\star}$ & $1.03,3.62$ \\
\hline Smaller than average & 3.16 & $0.60,16 \cdot 71$ & $1.90^{*}$ & $1.05,3.44$ & $1.99^{\star}$ & $1.10,3.59$ \\
\hline Very small & $7 \cdot 10^{*}$ & $1.43,35.35$ & $2 \cdot 76^{\star \star}$ & $1.40,5.44$ & $2 \cdot 87^{\star \star}$ & $1.46,5.63$ \\
\hline Underweight (WAZ <-2) & 0.68 & $0.42,1.09$ & 0.99 & $0.75,1.32$ & 0.96 & $0.71,1.30$ \\
\hline Minimum acceptable diet & 1.51 & $0.68,3.32$ & 0.81 & $0.53,1.24$ & 0.86 & $0.56,1.34$ \\
\hline Fe-rich foods & $1.67 \dagger$ & $0.97,2.87$ & 1.08 & $0.80,1.47$ & 1.09 & $0.80,1.47$ \\
\hline
\end{tabular}

$\mathrm{PF}$, plasma ferritin; TfR, soluble transferrin receptor; $\mathrm{HH}$, household; WAZ, weight-for-age $Z$-score.

${ }^{\star} P<0.05,{ }^{* *} P<0.01,{ }^{* \star *} P<0.001$.

$\dagger P<0 \cdot 1$.

$\ddagger$ Adjusted PF concentration $<12 \mu \mathrm{g} / \mathrm{I}^{\left({ }^{(18)}\right.}$

$\S \mathrm{TfR}$ concentration $>8.3 \mathrm{mg} / \mathrm{l}$.

$\| \alpha$-1-Acid glycoprotein $>1 \mathrm{~g} / \mathrm{l}$ or C-reactive protein $>5 \mathrm{mg} / \mathrm{l}$.

I Maternal height $<145 \mathrm{~cm}$.

had consumed any Fe-rich foods, but also due to a hypothesised small quantity consumed. Additionally, our measure of consumption of Fe-rich foods captured intake for only $1 \mathrm{~d}$ (previous 24h) of any such foods rather than the usual intake. Although the present study did not measure amounts consumed, a previous study has highlighted the fact that small amounts of complementary foods are indeed a major constraint in Bangladesh in this age group ${ }^{(25)}$. The study showed that although meal frequency and energy density of complementary foods were consistent with recommendations, foods were generally of low micronutrient density and offered in small amounts, resulting in low micronutrient intakes among infants during the second half of infancy ${ }^{(25)}$. Additionally, a recent analysis of $24 \mathrm{~h}$ dietary recalls among Bangladeshi children aged 6-23 months has also shown that only $10 \%$ of children met their recommended daily Fe intake requirements ${ }^{(26)}$. This is particularly striking, given that this sample included children in their second year of life who are more likely than infants of 6-11 months of age to consume Fe-rich foods. It is, therefore, likely that the lack of an observed association between consumption of Fe-rich foods and ID in our sample is due to a combination of a low proportion of children having consumed such foods and those who did with insufficient intakes. The contribution of Fe-rich foods to Fe intake is, therefore, likely to be insufficient to fulfil the dietary Fe requirements of rapidly growing infants.

In the present study, a significant sex difference was observed in the risk of anaemia and ID, with male children being at a greater risk. Several studies have corroborated these findings globally ${ }^{(27-29)}$, but not in Bangladesh $^{(20,21)}$. Several biological mechanisms have been postulated including that boys have lower body Fe stores at birth or higher intestinal Fe losses than girls or that genetic or hormonal factors may play a role ${ }^{(27,30)}$. The evidence concerning intra-HH food distribution and a possible bias towards favouring male children is mixed. Data suggest that, in South Asia, in particular, there is a pro-male bias in food choice as well as in the quantity of food offered, although a considerable variation within the region is found ${ }^{(31)}$. These differences are likely to arise due to inequalities in the intra-HH distribution of food as 
well as in differences in real $v$. perceived food requirements of different members in the HH based on their age and sex. That males were consistently at a greater risk of developing anaemia and ID than females in the present study is noteworthy because it goes against conventional wisdom of a possible pro-male bias in intra-HH food distribution in South Asia, but is in line with the proposed biological mechanisms.

Although birth weight data were unavailable, information on the mothers' perception of the size of their newborn babies was collected. This variable was found to be significantly associated with ID, with babies perceived to be smaller than normal at birth being at a greater risk of developing ID. This finding is plausible, given the well-documented fact that low-birth-weight babies are more vulnerable to early Fe depletion ${ }^{(32)}$.

\section{Programmatic implications}

The results of the present study suggest that a multipronged strategy for anaemia control, as proposed by the National Strategy for Anaemia Prevention and Control in Bangla$\operatorname{desh}^{(11)}$, is needed to address anaemia in rural Bangladesh. First, given the strong contribution of Fe deficiency to anaemia and the very low consumption of Fe-rich foods in the population studied, innovative ways to improve access to, and demand for, Fe supplements, Fe-rich foods or Fe-fortified foods or products for infants and young children are essential. This can be achieved either through routine Fe supplementation or by improving complementary diets. Though routine low-dose Fe supplementation among children aged 6 months and above is recommended by the $\mathrm{WHO}^{(33)}$, it is rarely implemented at scale. Therefore, delivery of Fe through Fe-fortified complementary foods or home fortificants (e.g. Fe-fortified micronutrient powders or lipid-based nutrient supplements) may be programmatically more feasible. The evidence base of the impact of micronutrient-fortified complementary foods and home fortificants among infants and young children is substantial. Data from trials of commercially processed Fe-fortified complementary foods ${ }^{(34,35)}$ and home fortificants, including micronutrient powders and lipid-based nutrient supplements ${ }^{(35,36)}$, have shown that these result in significant increases in $\mathrm{Hb}$ and ferritin concentrations as well as in a reduced risk of anaemia and ID. However, a few studies have considered alternative, logistically feasible and relatively inexpensive distribution systems and delivery platforms that reduce the economic burden on $\mathrm{HH}$ or health systems of already costly products while simultaneously reaching at-risk populations ${ }^{(37)}$.

A second and complementary strategy is to coordinate with infection prevention and control strategies, given the high burden of subclinical infections evident among young children and its contribution to the development of anaemia. Interventions to reduce the prevalence of anaemia have been justifiably focused on parasitic disease control strategies, particularly malaria and soil-transmitted helminth infections. These interventions should be continued to be implemented. However, a renewed focus on water, sanitation and hygiene interventions is warranted, given the emerging hypothesis that environmental enteropathy is a major cause of child undernutrition and anaemia ${ }^{(38,39)}$. This condition, caused by faecal bacteria ingested in large quantities by young children, is characterised by small-intestine inflammation, impaired absorptive capacity and increased intestinal permeability. It is thought to be highly prevalent among infants and young children living in conditions of poor sanitation and hygiene, particularly in developing countries. Therefore, a central tenet of any anaemia prevention and control strategy where water, sanitation and hygiene conditions are suboptimal should also include the promotion of adequate sanitation facilities and hand-washing after faecal contact and before feeding to reduce or prevent the adverse effects of environmental enteropathy on child undernutrition. One of the several indicators used to assess environmental enteropathy includes systemic immune activation, partly measured by the elevated levels of markers of subclinical infection including AGP and CRP, which was prevalent among one in three infants in the present study.

In summary, the burden of anaemia and ID is very high in young rural Bangladeshi infants during the critical transition period of increased physiological Fe requirements corresponding to the early complementary feeding phase between 6 and 11 months of age. Neither dietary nor infection control interventions are sufficient on their own. The increasing prevalence of anaemia and ID during the first 3 months of the complementary feeding period highlights the need to support mothers to introduce $\mathrm{Fe}$ supplements or Fe-rich foods or products in their infants' diet as soon as they start giving them complementary foods. Concurrently, the high burden of subclinical infections and its contribution to anaemia and ID highlight the need to include water, sanitation and hygiene and parasitic disease control strategies to control anaemia and ID in this population. Coordination of these two broad strategies is essential if any reductions of anaemia and ID among infants and young children are to be achieved.

\section{Acknowledgements}

The present study was funded by the Global Alliance for Improved Nutrition and Alive \& Thrive, through a grant from the Bill \& Melinda Gates Foundation. The authors' contributions were as follows: P. M. was the principal investigator of the project and designed the study with R. R., K. K. S. and M. R.; R. R. wrote the manuscript and analysed and interpreted the data with A. K.; K. K. S. and F. R. coordinated and supervised the data collection. All authors reviewed multiple versions of the manuscript and provided comments. All authors approved the final manuscript. Conflict of interest statement: at the time of conducting the fieldwork, F. R. was affiliated with Global Alliance for Improved Nutrition, a notfor-profit organisation that supports and promotes infant and young child nutrition programmes. All the other authors have no conflicts of interest to declare.

\section{References}

1. WHO (2007) Assessing the Iron Status of Populations: Including Literature Reviews, 2nd ed. Geneva: World 
Health Organization/Centers for Disease Control and Prevention.

2. WHO (2008) Worldwide Prevalence of Anaemia 1993-2005: WHO Global Database on Anaemia. Geneva: World Health Organization.

3. Stoltzfus RJ, Chwaya HM, Montresor A, et al. (2000) Malaria, hookworms and recent fever are related to anemia and iron status indicators in 0- to 5-y old Zanzibari children and these relationships change with age. J Nutr 130, 1724-1733.

4. Lozoff B (2007) Iron deficiency and child development. Food Nutr Bull 28, S560-S571.

5. Lozoff B, Brittenham GM, Wolf AW, et al. (1988) Iron deficiency anemia and iron therapy effects on infant developmental test performance. Pediatrics 79, 981-995.

6. Beard JL (2001) Iron-deficiency anemia: reexamining the nature and magnitude of the public health problem: iron biology in immune function, muscle metabolism and neuronal functioning. J Nutr 131, 568S-580S.

7. Horton S \& Ross J (2003) The economics of iron deficiency. Food Policy 28, 51-75.

8. Domellöf M (2011) Iron requirements in infancy. Ann Nutr Metab 59, 59-63.

9. Weiss G \& Goodnough LT (2005) Anemia of chronic disease. $N$ Engl J Med 352, 1011-1023.

10. Nemeth E \& Ganz T (2006) Regulation of iron metabolism by hepcidin. Ann Rev Nutr 26, 323-342.

11. Institute of Public Health Nutrition (2007) National Strategy for Anaemia Prevention and Control in Bangladesh. Dhaka: Ministry of Health and Family Welfare, Government of the People's Republic of Bangladesh.

12. UNICEF (1990) UNICEF Strategy for Improved Nutrition of Children and Women in Developing Countries. New York, NY: UNICEF.

13. Erhardt JG, Estes JE, Pfeiffer CM, et al. (2004) Combined measurement of ferritin, soluble transferrin receptor, retinol binding protein, and C-reactive protein by an inexpensive, sensitive, and simple sandwich enzyme-linked immunosorbent assay technique. J Nutr 134, 3127-3132

14. Cogill B (2003) Anthropometric Indicators Measurement Guide. Washington, DC: Food and Nutrition Technical Assistance Project (FHI 360).

15. WHO (2008) Indicators for Assessing Infant and Young Child Feeding Practices: Conclusions of a Consensus Meeting, 6-8 November 2007, Washington, DC.

16. Thurnham DI, Mburu ASW, Mwaniki DL, et al. (2005) Micronutrients in childhood and the influence of subclinical inflammation. Proc Nutr Soc 64, 502-509.

17. WHO (2011) Haemoglobin Concentrations for the Diagnosis of Anaemia and Assessment of Severity. Geneva: World Health Organization.

18. Thurnham DI, Mccabe LD, Haldar S, et al. (2010) Adjusting plasma ferritin concentrations to remove the effects of subclinical inflammation in the assessment of iron deficiency: a meta-analysis. Am J Clin Nutr 92, 546-555.

19. WHO Multicentre Growth Reference Study Group (2006) WHO Child Growth Standards: Length/height-for-age, Weight-for-age, Weight-for-length, Weight-for-height and Body Mass Index-for-age: Methods and Development. Geneva: World Health Organization.

20. Eneroth H, Persson L-Å, El Arifeen S, et al. (2011) Infant anaemia is associated with infection, low birth weight and iron deficiency in rural Bangladesh. Acta Paediatr 100, 220-225.

21. Shakur YA, Choudhury N, Hyder SMZ, et al. (2009) Unexpectedly high early prevalence of anaemia in 6-month-old breast-fed infants in rural Bangladesh. Public Health Nutr 13, 4-11.

22. Siegel EH, Stoltzfus RJ, Khatry SK, et al. (2006) Epidemiology of anemia among 4- to 17-month children living in south central Nepal. Eur J Clin Nutr 60, 228-235.

23. Dewey KG (2001) Nutrition, growth, and complementary feeding of the breastfed infant. Pediatr Clin North Am $\mathbf{4 8}$ 87-104.

24. Meinzen-derr JK, Guerrero ML, Altaye M, et al. (2006) Risk of infant anemia is associated with exclusive breast-feeding and maternal anemia in a Mexican cohort. $J$ Nutr 136, 452-458.

25. Kimmons JE, Dewey KG, Haque E, et al. (2005) Low nutrient intakes among infants in rural Bangladesh are attributable to low intake and micronutrient density of complementary foods. J Nutr 135, 444-451.

26. Rasheed S, Haider R, Hassan N, et al. (2011) Why does nutrition deteriorate rapidly among children under 2 years of age? Using qualitative methods to understand community perspectives on complementary feeding practices in Bangladesh. Food Nutr Bull 32, 192-200.

27. Domellof M, Lonnerdal B, Dewey KG, et al. (2002) Sex differences in iron status during infancy. Pediatrics 110, $545-552$

28. Miller MF, Stoltzfus RJ, Mbuya NV, et al. (2003) Total body iron in HIV-positive and HIV-negative Zimbabwean newborns strongly predicts anemia throughout infancy and is predicted by maternal hemoglobin concentration. J Nutr 133, 3461-3468.

29. Yang Z, Lo B, Adu-Afarwuah S, et al. (2009) Prevalence and predictors of iron deficiency in fully breastfed infants at 6 mo of age: comparison of data from 6 studies. Am J Clin Nutr 89, $1433-1440$.

30. Wieringa FT, Berger J, Dijkhuizen MA, et al. (2007) Sex differences in prevalence of anaemia and iron deficiency in infancy in a large multi-country trial in South-East Asia. $\mathrm{Br}$ J Nutr 98, 1070-1076.

31. Haddad L, Pena C, Nishida C, et al. (1996) Food Security and Nutrition Implications of Intra-housebold Bias: A Review of Literature. FCND Discussion Paper no. 19. Washington, DC: International Food Policy Research Institute.

32. Stoltzfus RJ (2011) Iron interventions for women and children in low-income countries. J Nutr 141, 756S-762S.

33. Stoltzfus RJ \& Dreyfuss M (1998) Guidelines for the Use of Iron Supplements to Prevent and Treat Iron Deficiency Anemia. Washington, DC: International Nutritional Anemia Consultative Group.

34. Gera T, Sachdev HS \& Boy E (2012) Effect of iron-fortified foods on hematologic and biological outcomes: systematic review of randomized controlled trials. Am J Clin Nutr 96, 309-324.

35. Dewey KG \& Adu-afarwuah S (2008) Systematic review of the efficacy and effectiveness of complementary feeding interventions in developing countries. Matern Child Nutr 4, 24-85.

36. De-Regil LM, Suchdev PS, Vist GE, et al. (2011) Home fortification of foods with multiple micronutrient powders for health and nutrition in children under two years of age. Cochrane Database of Systematic Reviews 2011, issue 9 CD008959.

37. Olney DK, Rawat R \& Ruel MT (2012) Identifying potential programs and platforms to deliver multiple micronutrient interventions. J Nutr 142, 178S-185S.

38. Humphrey JH (2009) Child undernutrition, tropical enteropathy, toilets, and handwashing. Lancet 19, 1032-1035.

39. Prendergast A \& Kelly P (2012) Enteropathies in the developing world: neglected effects on global health. Am J Trop Med Hyg 86, 756-763. 